\title{
Hadits Tentang Evaluasi Pendidikan dan Karakteristiknya
}

\author{
Levi Fitriani ${ }^{*}$, Ayu Lika Rahmadani ${ }^{2}$, M. Aufar Saputra Pratama \\ Erawan $^{3}$ \\ 1,2UIN Sunan Kalijaga Yogyakarta, ${ }^{3}$ Universitas Muhammadiyah Yogyakarta \\ Email: levilevi811@gmail.com¹ ${ }^{1}$ ayulikaramadhani22@gmail.com² \\ m.aufar.psc20@mail.umy.ac.id ${ }^{3}$
}

\begin{abstract}
Educational evaluation is very essential to determine the success obtained by students, An educational evaluation also serves to see whether the programs that have been implemented have useful improvements to make the program more effective. In addition, the assessment is to decide the degree of progress of the program in training. During the time spent in Islamic training, the best approach to discover how fruitful the learning targets or member's ability is by assessing. The strategy utilized in this investigation is the examination of writing content identified with the hadith about instructive assessment. The consequences of this investigation show that instructive assessment is a cycle to decide the benefit of something identified with Islamic training, the strategy for understanding the study of hadith (fiqh al-hadith) is a measurement that is no less significant after dirayah science and musthalah hadith. This is on the grounds that fiqh al-hadits is an investigation that attempts to profoundly investigate and comprehend the messages contained in the Prophet's hadith to be drilled.
\end{abstract}

Keywords: Hadith, Educational Evaluation, Characteristics

\begin{abstract}
Abstrak
Evaluasi pendidikan sangat diperlukan untuk mengetahui keberhasilan yang diperoleh peserta didik, evaluasi pendidikan sangat penting dilakukan dalam proses pendidikan karena evaluasi berfungsi untuk melihat dan mengkoreksi apakah dalam programprogram yang telah dilaksanakan perbaikan-perbaikan yang berguna untuk membuat program tersebut menjadi lebih efektif. evaluasi juga bertujuan untuk mengetahui taraf kemajuan dari
\end{abstract}


pendidikan. Dalam proses pendidikan Islam cara untuk mengetahui bagaimana keberhasilan dari tujuan pembelajaran atau kompetensi peserta yaitu dengan adanya evaluasi. Metode dalam penulisan yaitu menggunakan metode kepustakaan (library research), pendekatan yang dipakai yaitu analisis isi (content analisys), dan menggunakan sumber primer dan sekunder yang berkaitan dengan evaluasi pendidikan. Hasil penelitian ini menunjukkan bahwa evaluasi pendidikan merupakan sebuah usaha dalam menentukan nilai dari dari suatu hal yang berkaitan dengan pendidikan Islam, metode pemahaman ilmu hadits (figh al-hadits) atau pemahaman hadits dengan mengerti maknanya bisa dikatakan sebagai dimensi yang urgen setelah memahai ilmu dirayah dan musthalah hadits. Hal ini disebabkan karena fiqh al-hadits merupakan sebuah proses pengupasan dan kajian yang mendalam dan juga memberikan pemahaman dalam pesan yang terkandung pada hadits Nabi untuk bisa diamalkan.

Kata Kunci: Hadits, Evaluasi Pendidikan, Karakteristik

\section{Pendahuluan}

Tugas dan tujuan utama hidup manusia adalah untuk berkembang dan memperbarui diri dalam mencari sebuah makna. Maka upaya untuk melakukannya, adalah dengan pendidikan Islam. ${ }^{1}$ Bagi peserta didik muslim, pendidikan Islam merupakan serangkaian pengalaman tambahan yang bertujuan untuk menanamkan pengetahuan dan nilai-nilai yang mempromosikan perkembangan karakter, ${ }^{2}$ spiritual, moral, budaya, emosional, intelektual, sosial, ${ }^{3}$ menjadi pribadi yang terhormat, serta sopan santun mengenai koeksistensi kelompok agama dan budaya yang berbeda. ${ }^{4}$

\footnotetext{
${ }^{1}$ Jeffrey Guhin, "The Boundaries of Pragmatism in Muslim Education: Comparing the Islamic Pedagogies of Sayyid Qutb and Fethullah Gülen," Critical Research on Religion 8, no. 3 (2020): 257-722.

2 Zaniah Marshallsay, "Twists and Turns of Islamic Education across the Islamic World," International Journal of Pedagogies and Learning 7, no. 3 (2012): 180-190.

${ }^{3}$ Glenn Hardaker and Aishah Ahmad Sabki, "A Spiritual Understanding of Islamic Education," in Pedagogy in Islamic Education (Emerald Publishing Limited, 2018), 5562.

${ }^{4}$ Maali Mohammed Jassim Alabdulhadi, "Religious Tolerance in Secondary Islamic Education Textbooks in Kuwait," British Journal of Religious Education 41, no. 4 (2019): 422-434.
} 
Dalam Islam, pendidikan memainkan peran sentral dalam perkembangan kehidupan seperti yang dijelaskan dalam Al-Qur'an (lihat Surah 20: 114; Surah 58:11; Surah 39:9; Surah 2:170; Surah 17:36; Surah 6: 148). Hal ini membuktikan bahwa pendidikan dan tradisi keilmuan dalam Islam telah tertanam jauh sebelum era sains modern datang. ${ }^{5}$ Pendidikan Islam didorong oleh motivasi manusia untuk menghindari apa yang dipandang salah dan cita-cita utamanya adalah melakukan apa yang dipandang benar. ${ }^{6}$ Maka dari itu, Islam berpandangan bahwa penanaman potensi individu diharapkan dapat memungkinkan individu untuk hidup rukun dengan orang lain ketika penanaman itu didasarkan pada Al-Qur'an dan Hadits. ${ }^{7}$

Menurut Husin dan Tamuri (2019), pendidikan agama sangat penting dalam Islam karena ibadah dilakukan sepanjang waktu akan diperhitungkan sepanjang hidup seorang muslim, termasuk perbuatan, pikiran, dan perasaannya. Hal inilah yang pada akhirnya akan memberikan bimbingan, pembiasaan, serta mendidik umat muslim agar menjadi insan yang sesungguhnya, berakhlakul karimah, dan yang taat kepada Allah SWT. ${ }^{8}$ Apabila seseorang sudah beriman dengan benar serta selalu senantiasa beribadah kemudian istiqomah di jalan Allah SWT, inilah yang nantinya diharapkan agar dapat mencapai level insan kamil yang memiliki akhlakul karimah dan terpuji serta mampu untuk menetapkan kodrat manusia diciptakan ialah sebagai khalifah di bumi pada diri mereka masing-masing. ${ }^{9}$

\footnotetext{
${ }^{5}$ Nur Asnawi and Nina Dwi Setyaningsih, "Perceived Service Quality in Indonesian Islamic Higher Education Context: A Test of Islamic Higher Education Service Quality (i-HESQUAL) Model," Journal of International Education in Business 13, no. 1 (2020): 107-130.

"Glenn Hardaker and Aishah Ahmad Sabki, "The Rise of the Islamic Institution," Pedagogy in Islamic Education, (2018), 3-16.

7 Abdur Rafik and Anjar Priyono, "A New Insight into Alumni Satisfaction Model for Islamic Higher Education Institutions (IHEI)," Management Research Review 41, no. 12 (2018): 1411-1437.

${ }^{8}$ Nur Hanani Hussin and Ab Halim Tamuri, "Embedding Values in Teaching Islamic Education among Excellent Teachers," Journal for Multicultural Education 13, no. 1 (2019): 2-18.

${ }^{9}$ Mohd Khambali Hambali Khadijah et al., "Al-Wasatiyyah in the Practice of Religious Tolerance among the Families of New Muslims in Sustaining a Well-Being Society," Humanomics 33, no. 2 (2017): 211-220.
} 
Karenanya, hal ini memerlukan rencana yang sesuai dengan pedoman yang jelas, yaitu melalui pembiasaan, pengarahan, dan penanaman nilai-nilai Islami dalam diri peserta didik. Ini yang kita butuhkan melalui pendidikan Islam. ${ }^{10}$ Kendati demikian, pendidikan Islam memiliki visi dan misi sebagai dasar untuk melancarkan program-program yang akan dijalankan yang mana orientasinya adalah untuk keberhasilan dari pencapaian visi dan misi dari pendidikan Islam. ${ }^{11}$

Keberhasilan dari suatu program dalam mencapai visi dan misinya memerlukan evaluasi dan penilaian. Evaluasi dan penilaian berfungsi sebagai cara untuk melihat seperti apakah programprogram yang telah dilaksanakan dan apa saja perbaikan-perbaikan yang berguna untuk membuat program tersebut menjadi lebih efektif. ${ }^{12}$

Selain itu adanya evaluasi sebagai upaya mengetahui taraf kemajuan dari program dalam pendidikan tersebut. Dalam proses pendidikan Islam cara untuk mengetahui bagaimana keberhasilan dari tujuan pembelajaran atau kompetensi peserta yaitu dengan adanya evaluasi. Evaluasi ini bisa dikatakan sebagai alat yang dapat dilakukan untuk bisa mengetahui apakah tujuan dari proses pembelajaran yang telah dilakukan sudah tercapai dengan cara yang efektif ataukah masih memerlukan perbaikan. ${ }^{13}$

Dalam proses evaluasi tentu memiliki cara yang efektif dan juga sistematis karena proses evaluasi juga tidak bisa dilakukan hanya dengan sekedar menilai pembelajaran tersebut berhasil atau tidak akan tetapi harus sesuai dengan kaidah evaluasi yang sesungguhnya. Sederhananya karakteristik yang harus ada dalam evaluasi pembelajaran yang efektif dan efisien yaitu instrumen yang jelas,

\footnotetext{
10 Aman Rassouli and Necdet Osam, "English Language Education Throughout Islamic Republic Reign in Iran: Government Policies and People's Attitudes," SAGE Open 9, no. 2 (April 1, 2019): 1-11.

${ }^{11}$ Lia Mega Sari, "Evaluasi Dalam Pendidikan Islam," Al-Tazkiyah Jurnal Pendidikan Islam 9, no. 2 (2018): 211-231.

12 Andrew Gitlin and John Smyth, "Dominant' View of Teacher Evaluation and Appraisal: An International Perspective," Journal of Education for Teaching 14, no. 3 (January 1988): 237-257.

${ }^{13}$ Ismail Marzuki and Lukmanul Hakim, "Evaluasi Pendidikan Islam," Jurnal Tadarus Tarbawy 1, no. 1 (2019): 77-84.
} 
reliabel, relevan, representatif, praktis, deskriminatif, spesifik dan proprsional. ${ }^{14}$

Evaluasi merupakan komponen penting dari sistem pendidikan Islam yang wajib dilakukan terus menerus dan juga terencana jadi harus dilakukan seefektif mungkin. ${ }^{15}$ Dalam pendidikan Islam pastinya setiap proses kehidupan selalu bergantung pada alQur'an dan hadits. ${ }^{16}{ }^{17}$ Apalagi pelatihan, segala sesuatu yang diidentikkan dengan persekolahan harus memiliki pendirian yang kokoh dan jelas yang bersumber dari al-Qur'an dan hadits. Oleh karena itu, sejauh penilaian instruktif, khususnya yang berkaitan dengan premis hadits tentang penilaian sekolah dan kualitasnya. ${ }^{18}$

\section{Pembahasan}

\section{a. Pengertian Evaluasi Pendidikan}

Pengertian evaluasi secara etimologi merupaka serapan kata yang asal katanya merupakan serapan dari bahasa Inggris yaitu evaluation. Asal katanya yaitu evaluation ini sendiri. Sedangkan asal kata value yang memiliki arti nilai. ${ }^{19}$ Sedangkan dalam artian bahasa Arab yaitu tatsmiim, taqyiim atau taqdir. ${ }^{20}$

Dalam dunia pendidikan pada awalnya pengertian evaluasi pendidikan selalu dikaitkan dengan prestasi belajar siswa. Secara teoritis beberapa ahli pendidikan mengemukakan definisi evaluasi, diantaranya Scriven (2003) yang mengatakan evaluasi adalah proses menentukan manfaat, nilai, atau signifikansi dari hal-hal (mendekati

${ }^{14}$ Wang Zhanjun, Qiao Weifeng, and Li Jiangbo, "Data-Intensive Evaluation: The Concept, Methods, and Prospects of Higher Education Monitoring Evaluation," Chinese Education and Society 49, no. 1-2 (2016): 86-98.

${ }^{15}$ Siti Kholidatur Rodiyah, "Ideal Evaluation in Islamic Education Learning," Edutec: Journal Of Education And Technology 2, no. 2 (2019): 1-5.

16 Ahmad Atabik, "Story Repetition in Qur'an as an Islamic Education Learning Strategy," Edukasia: Jurnal Penelitian Pendidikan Islam 15, no. 2 (2020): 354.

17 Waqar Un Nisa Faizi and Naeem Butt, "The Origins of Islamic Educational Reformations," Al-Idah 38, no. 2 (2020).

${ }^{18}$ Nurul Zainab, "Model Evaluasi Pendidikan Berbasis Proses Menurut Hadis," Jurnal Al-Banjari 17, no. 1 (2018): 153-172.

${ }^{19}$ Ibadullah Malawi and Endang Sri Maruti, Evaluasi Pendidikan (Magetan: CV. Ae Media Grafika, 2016).

20 Ahmad Warson Munawwir, Kamus Al-Munawwir Arab Indonesia Terlengkap (Surabaya: Pustaka Progresif, 2002). 
sinonim adalah kualitas/nilai/penting). Laporan hasil dari proses ini disebut evaluasi jika kompleks, klaim evaluatif jika kalimat sederhana, dan kami di sini menggunakan istilah evaluand untuk apa pun yang dievaluasi (opsional, kami menggunakan evaluee untuk menunjukkan bahwa evaluand adalah seseorang). ${ }^{21}$

Definisi yang lebih luas, dikemukakan oleh Kellaghan dan Stufflebeam (2003), bahwasanya proses evaluasi bukan sekedar mengukur sejauh mana tujuan tercapai, tetapi juga digunakan untuk membuat keputusan. ${ }^{22}$

Kemudian Maulida (2015), menjekaskan sebuah proses evaluasi meliputi dua hal: pertama, mengukur, yaitu membandingkan sesuatu dengan ukuran. Dengan demikian pengukuran bersifat kuantitatif; dan kedua, menilai, yaitu mengambil suatu keputusan terhadap sesuatu dengan ukuran baik atau buruk. ${ }^{23}$ Dengan demikian penilaiannya bersifat kualitatif. Dalam pendidikan Islam evaluasi yaitu sebuah proses untuk menentukan nilai dari dari suatu hal yang berkaitan dengan pendidikan Islam. ${ }^{24}$

Lebih lanjut, evaluasi pendidikan dalam Islam adalah kegiatan penilaian terhadap proses pendidikan Islam yang dilaksanakan sedangkan sasaran evaluasi pendidikan Islam adalah peserta dalam pendidikan Islam meliputi evaluasi terkait penguasaan pengetahuan pendidikan Islam, keterampilan, dan kegiatan pengamalan ajaran Islam. ${ }^{25}$

Diperkuat lagi oleh Zuhairini (1995), evaluasi pendidikan Islam adalah suatu kegiatan untuk menentukan taraf kemajuan suatu aktivitas dalam rangka mengetahui tingkat keberhasilan seorang pendidik dalam menyampaikan materi pelajaran, menemukan

\footnotetext{
${ }^{21}$ Michael Scriven, "Evaluation Theory and Metatheory," International Handbook of Educational Evaluation 9 (2003): 15-30.

${ }^{22}$ Thomas Kellaghan and Daniel L. Stufflebeam, International Handbook of Educational Evaluation, International Handbook of Educational Evaluation (Springer Netherlands, 2003).

${ }^{23}$ Ali Maulida, "Metode Dan Evaluasi Pendidikan Akhlak Dalam Hadits Nabawi," Edukasi Islami Jurnal Pendidikan Islam 04, no. 07 (2015): 855-869.

${ }^{24}$ Zainab, Op. Cit., 153-172.

25 Halid Hanafi, La Adu, and Zainuddin, Ilmu Pendidikan Islam (Yogyakarta: Deepublish, 2018).
} 
kelemahan-kelemahan yang dilakukan, baik berkaitan dengan materi, metode, fasilitas, dan sebagainya. ${ }^{26}$

Beberapa penjelasan tersebut di atas dapat disimpulkan bahwa evaluasi pendidikan merupakan sebuah proses penilaian yang mempermudah pendidik mengukur pencapaian tujuan pendidikan Islam yang dilakukan, mempermudah peserta didik mengetahui tingkat pencapaian pendidikan Islam yang diikuti, bagi pengelola pendidikan dapat mengetahui berbagai persoalan terkait pengelolaan pendidikan Islam dan pengambilan kebijakan-kebijakan terkait pengelolaan pendidikan Islam, seperti inilah seharusnya fungsi dari evaluasi pendidikan Islam.

\section{b. Tujuan Evaluasi Pendidikan}

Berdasarkan pemikiran filosofis, membentuk manusia paripurna (al-insan al-kamil) ${ }^{27}$ adalah tugas dari pendidikan Islam..$^{28}$ Dalam proses evaluasi pendidikan Islam hasil akhirnya harus mengarah pada dua dimensi, pertama yaitu dimensi dialektikal horizontal dan kedua dimensi ketundukan vertikal. ${ }^{29}$ Evaluasi pendidikan memiliki tujuan untuk mengetahui seberapa jauh pemahaman peserta didik dalam memahami materi pelajaran, memiliki jiwa yang berani, melatih peserta didik agar memiliki kemampuan dalam mengingat apa saja pelajaran-pelajaran dan ilmu yang telah mereka terima dan mereka pelajari, selain itu juga bertujuan untuk mengetahui siapa saja diantara peserta didik yang memiliki prestasi. ${ }^{30}{ }^{31}$ Evaluasi pendidikan juga berlaku untuk para

\footnotetext{
${ }^{26}$ Zuhairini, Filsafat Pendidikan Islam (Jakarta: Bumi Aksara, 1995).

${ }^{27}$ Nuraan Davids and Yusef Waghid, "Ibn Al-Arabi's Idea of Al-Insan Al-Kamil (the Perfect Human) and Democratic Education," Democratic Education and Muslim Philosophy, 2019, 71-79.

${ }^{28}$ Deswita Deswita, "Pendidikan Berbasis Kecerdasan Ruhaniah (Membentuk Insan Paripurna/Insan Al-Kamil)," Ta'dib: Jurnal Pendidikan Islam 13, no. 2 (2016): 186-197.

${ }^{29}$ Choirul Mahfud, "Evaluation of Islamic Education Curriculum Policy in Indonesia," Premiere Educandum: Jurnal Pendidikan Dasar Dan Pembelajaran 9, no. 1 (2019): 34-43.

30 Helen Sabera Adib et al., "Evaluation of Islam Education Teachers Training Implementation," Jurnal Penelitian Dan Evaluasi Pendidikan 23, no. 2 (2019): 106-116.

31 Siti Asiah Tjabolo and Lian Gafar Otaya, "The Evaluation of Islamic Education Teachers' Performance," Jurnal Pendidikan Islam 5, no. 1 (2019): 25-38.
} 
pendidik, sejauh mana mereka menjalankan tugasnya untuk mencapai tujuan pendidikan. ${ }^{32}$

Menurut T. Manichander (2016), evaluasi pendidikan dilakukan dari waktu ke waktu untuk tujuan berikut:

1. Untuk menentukan efektivitas relatif program dalam hal keluaran perilaku siswa; Pengukuran dan Evaluasi dalam Pendidikan

2. Untuk membuat keputusan yang dapat diandalkan tentang perencanaan pendidikan

3. Untuk memastikan nilai waktu, energi dan sumber daya yang diinvestasikan dalam suatu program

4. Untuk mengidentifikasi pertumbuhan atau kurangnya pertumbuhan siswa dalam memperoleh pengetahuan, keterampilan, sikap dan nilai-nilai sosial yang diinginkan

5. Membantu guru menentukan keefektifan teknik mengajar dan materi pembelajaran

6. Untuk membantu memotivasi siswa agar mau belajar lebih banyak ketika mereka menemukan kemajuan atau kekurangan kemajuan mereka dalam tugas-tugas yang diberikan

7. Mendorong siswa untuk mengembangkan rasa disiplin dan kebiasaan belajar yang sistematis

8. Untuk menyediakan administrator pendidikan dengan informasi yang memadai tentang efektivitas guru dan kebutuhan sekolah

9. Untuk memperkenalkan orang tua atau wali dengan pertunjukan anak-anak mereka

10. Untuk mengidentifikasi masalah yang mungkin menghambat atau mencegah pencapaian tujuan yang ditetapkan

11. Memprediksi kecenderungan umum perkembangan proses belajar-mengajar

12. Untuk memastikan pengelolaan sumber daya yang langka secara ekonomis dan efisien

13. Memberikan dasar yang obyektif untuk menentukan kenaikan pangkat siswa dari satu kelas ke kelas lainnya serta pemberian sertifikat

${ }^{32}$ Miswanto, "Evaluasi Pendidikan Agama Islam Berbasis Karakter," Jurnall Ilmiah Madaniyah 4, no. 2 (2014): 151-164. 
14. Untuk memberikan dasar yang adil untuk menentukan pada tingkat pendidikan apa pemilik sertifikat harus memasuki karir. ${ }^{33}$

Maka dapat dimaknai, bahwa evaluasi pendidikan adalah proses sistematis untuk menentukan pertumbuhan dan kemajuan siswa menuju tujuan atau nilai-nilai dalam kurikulum. Dengan kata lain, itu adalah proses sistematis untuk menentukan sejauh mana tujuan pendidikan dicapai oleh siswa. Evaluasi pendidikan adalah suatu proses sistematis yang berarti menghilangkan cara-cara dan sarana yang santai, tidak terkendali, tidak sistematis untuk menilai kemajuan siswa. ${ }^{34}$ Kedua, evaluasi pendidikan berusaha untuk menilai kemajuan siswa menuju tujuan dalam kurikulum. Ini mengharuskan tujuan dalam keseluruhan kurikulum yaitu tujuan pendidikan harus ditentukan sebelumnya. Karena tidak mungkin menilai pertumbuhan dan kemajuan siswa menuju tujuan atau nilai-nilai dalam kurikulum tanpa terlebih dahulu menentukan tujuan pendidikan. ${ }^{35}$

\section{c. Manfaaat Evaluasi Pendidikan}

Melaksanakan suatu evaluasi pembelajaran tidaklah mudah tanpa tujuan dan manfaat, begitu pula ketika melakukan tes formatif kepada siswa. Tes formatif yang dimaksud di sini adalah tes yang bertujuan untuk mengetahui sejauh mana siswa telah terbentuk setelah mengikuti suatu program tertentu. Berikut adalah manfaat tes formatif:

a. Bagi Peserta Didik

1) Peserta didik dapat melihat berhasil atau tidaknya pembelajarannya

2) Peserta didik dapat mengetahui sebatas mana pelajaran yang diberikan pendidik yang berhasil mereka pahami.

b. Bagi Pendidik

1) Pendidik dapat mengetahui siapa saja siswa yang memiliki prestasi akademik di kelasnya

\footnotetext{
${ }^{33}$ T. Manichander, Evaluation in Education (Hillsborough St, Raleigh: Lulu Publication, 2016).

${ }^{34}$ Istvan Szokol and Kinga Horvath, "The Dimensions of Educational Evaluation," Kepzes Es Gyakorlat 14, no. 3-4 (2016).

35 Ar Saravanakumar, Shanmugarevathi, and G.Revathi, Educational Evaluation (Madurai: Shanlax Publications, 2019).
} 
2) Pendidik akan tahu sudah atau belum tepatnya materi yang diberikannya

3) Pendidik dapat mengetahui sudah atau belum tepatnya metode yang digunakannya dalam mengajar

c. Bagi sekolah

1) Suasana belajar yang berlangsung di sekolah dapat diketahui

2) Dapat mengetahui informasi yang diberikan guru tentang kurikulum yang sudah sesuai atau belum, agar menjadi bahan pertimbangan kedepannya untuk perencanaan sekolah

3) Dapat mengetahui informasi terkait hasil dari penilaian yang didapatkan setiap tahun bisa menjadi pedoman bagi sekolah, dan standar sudah terpenuhi atau belum, sebab standar akan terpenuhi dengankuantitas yang bagus yang sudah didapatkan. ${ }^{36}$

Menurut Arikunto (1993), tes formatif dilakukan dengan tujuan untuk mengetahui sejauh mana siswa telah berhasil setelah mengikuti suatu program tertentu. ${ }^{37}$

\section{d. Syarat Evaluasi Pendidikan Islam}

Dalam evaluasi pendidikan Islam, syarat yang harus dipenuhi, yaitu:

a. Keabsahan

b. Dapat diandalkan

c. Efisiensi ${ }^{38}$.

\section{e. Prinsip-prinsip Evaluasi Pendidikan Islam}

Menurut Zubaidillah (2018) dan Acree (2019), untuk mendapatkan hasil yang baik dan akurat dalam pelaksanaan evaluasi harus memperhatikan prinsip-prinsipnya, yakni sebagai berikut: 1) Komprehensif; 2) Komparatif; 3) Kontinyu; 4) Adil dan Objektif; 5) Criteria yang valid; 6) Fungsional; 7) Diagnostik; 8) Keterpaduan; 9)

\footnotetext{
${ }^{36}$ Supriyadi, Evaluasi Pendidikan (Pekalongan: Nasya Expanding, 2021).

${ }^{37}$ Suharsimi Arikunto, Dasar-Dasar Evaluasi Pendidikan (Jakarta: Bumi Aksara, 1993).

${ }^{38}$ Marzuki and Hakim, Op. Cit., 77-84.
} 
Keterlibatan peserta didik; 10) Koherensi; 11) Pedagogis; 12) Akuntabel; dan 13) Praktis. ${ }^{39} 40$

Adapun kaitannya dengan evaluasi pendidikan Islam yaitu: 1) Sikap dan pengamalan terhadap arti hubungan pribadinya dengan tuhan; 2) Sikap dan pengamalam terhadap arti hubungan diri dengan masyarakat; 3) Sikap dan pengamalam terhadap arti hubungan kehidupannya dengan alam dan sekitarnya; 4) Sikap dan pandanganya terhadap dirinya sendiri selaku hamba Allah dan selaku anggota masyarakatnya serta selaku khalifah di bumi Allah. ${ }^{41}$

\section{f. Karakteristik Hadits Evaluasi Pendidikan Islam}

Dalam Islam hadits mempunyai kedudukan yang sangat penting. Karena salah satu sumber hukum setelah al-Qur'an ialah hadits. Tanpa hadits al-Qur'an akan sulit dipahami. Dengan tidaknya mengambil landasan hadits dalam menggunakan al-Qur'an adalah hal yang tidak mungkin, karena keduanya tidak dapat dipisahkan satu sama lain. ${ }^{42}$ Meskipun menurut Tasbih (2017), ada satu titik dalam sejarah Islam ketika kelompok Muslim atau non-Muslim tertentu menyangkal mengakui hadits. Penyangkalan ini adalah karena ketidaktahuan mereka terhadap arti sebenarnya dari Al-Qur'an dan hadits itu sendiri. ${ }^{43}$ Maka sudah sepantasnya memahami kedua sumber hukum itu menjadi hal yang utama, jika terjadi kesalahan pemahaman diantara keduanya akan merusak eksistensi sumber hukum tersebut. Dengan memahami dua sumber hukum yaitu alQur'an dan Hadits, anda akan mendapatkan petunjuk hukum yang

39 Muh Haris Zubaidillah, "Prinsip Dan Alat Evaluasi Dalam Pendidikan," OSF Preprints, 2018, 1-13.

40 Jeremy Acree, "Applying the Collaborative Approaches to Evaluation (CAE) Principles in an Educational Evaluation: Reflections from the Field," Canadian Journal of Program Evaluation 34, no. 2 (2019): 272-281.

${ }^{41}$ Surawan and Muhammad Athaillah, Ilmu Pendidikan Islam (Yogyakarta: K-Media, 2021).

42 Arim Zufaida Amna, "Hadis Sebagai Sumber Hukum Islam (Studi Kasus Pandangan Masyarakat Desa Besito-Kudus Terhadap Hadis Larangan Tertawa)," Syariah: Journal of Islamic Law 2, no. 2 (2020): 64-87.

43 Tasbih Tasbih, "Kedudukan Dan Fungsi Hadis Sebagai Sumber Hukum Islam," Jurnal Ushuluddin: Media Dialog Pemikiran Islam 14, no. 3 (March 28, 2017): 331-341. 
sesuai dengan tuntunan syariat dan sunnah nabi Muhammad. ${ }^{44}$ Mengingat kedudukan hadits sebagai sumber hukum Islam setelah alQur'an. Hal ini mengandung pengertian bahwa ketika tidak ditemukan di dalam al-Qur'an yang berkaitan dengan hukum, maka para ulama sepakat harus merujuk kepada hadits Nabi. ${ }^{45}$ Kemudian diperkuat oleh Ali dan Himmawan (2019), mengenai kedudukan hadits sebagai sumber hukum Islam, bahwa temuan dalam risetnya mengatakan; Imam asy-Syafi'i berpegang pada pendapat bahwa ketentuan-ketentuan dalam hadits berada dalam hukum-hukum alQur'an, karena wujud perintah yang ada pada keduanya adalah pangkal dari sumber yang sama, meskipun melalui jalur yang berbeda. ${ }^{46}$

Selain sebagai sumber ajaran Islam, al-Qur'an juga merupakan sumber pertama dan hadits merupakan sumber kedua, dan bahkan keduanya sangat sulit dipisahkan sebab keduanya merupakan wahyu, perbedaannya al-Qur'an merupakan wahyu yang dibaca langsung oleh Allah Swt. ${ }^{47}$ Sedangkan hadits wahyu yang tidak dibaca langsung oleh Allah Swt. Dalam hadits tidak dilakukan dengan sembarangan, kehati-hatian dalam kualitas keshahihan hadits ini menjadi hal yang mutlak karena kita akan menggunakannya sebagai pedoman hidup. ${ }^{48}$

Membahas tentang kajian terhadap hadits-hadits Nabi tentu tidak terbatas pada kajian ilmu riwayah atau dirayah saja tetapi harus meluaskan pembahasannya. Akan tetapi kendatipun demikian ilmu riwayah dan dirayah hadits lebih populer dibandingkan dengan aspek-aspek kajian hadits lainnya. ${ }^{49}$ Dari beberapa bagian kajian ilmu hadits, teknik pemahaman kajian hadits (figh al-hadits) barangkali

\footnotetext{
${ }^{44}$ Septi Aji Fitra Jaya, "Al-Qur'an Dan Hadis Sebagai Sumber Hukum Islam," Jurnal Indo-Islamika 9, no. 2 (2019): 204-216.

${ }^{45}$ Fatkhul Wahab, "Kedudukan Hadis Dalam Penetapan Hukum," Maqashid: Jurnal Hukum Islam 2, no. 1 (2019): 1-14.

${ }^{46}$ Muhammad Ali and Didik Himmawan, "Peran Hadits Sebagai Sumber Ajaran Agama, Dalil-Dalil Kehujjahan Hadits Dan Fungsi Hadits Terhadap Al-Qur'an," Risalah: Jurnal Pendidikan Dan Studi Islam 5, no. 1 (2019): 125-132.

${ }^{47}$ Kaharuddin Kaharuddin and Abdus Sahid, "Hadis Sebagai Sumber Hukum Islam: (Tinjauan Paham Inkar As-Sunnah, Syi'ah, Dan Orientalis)," Tajdid: Jurnal Pemikiran Keislaman Dan Kemanusiaan 2, no. 2 (2018): 457-467.

${ }^{48}$ Ali and Himmawan, Ibid., 125-132.

${ }^{49}$ Siti Syamsiyatul Ummah, “Digitalisasi Hadis (Studi Hadis Di Era Digital)," Diroyah: Jurnal Studi Ilmu Hadis 4, no. 1 (2019): 1-10.
} 
menjadi tolak ukur utama setelah kajian dirayah dan musthalah hadits. Hal ini dengan alasan bahwa interaksi figh al-hadits merupakan sebuah kajian yang melihat untuk menyelidiki secara mendalam dalam memahami pesan-pesan yang terkandung dalam hadits Nabi untuk mendapatkan pertanyaan dalam masalah kehidupan dan selanjutnya memiliki pilihan untuk mengamalkannya. ${ }^{50}$

Memahami perbedaan atribut hadits pada tataran matan sesungguhnya merupakan sistem fundamental dalam memahami hadits Nabi (figh al-hadits). Jai, pada hakekatnya figh al-hadits bercirikan sebagai ilmu yang mengkaji urgensi yang didapat dari kepingankepingan lafaz hadits dan kemaknaan ideal kata pengelola. ${ }^{51}$

Dikutip dari buku "hadits tentang pendidikan" hadits dari evaluasi pendidikan yaitu:

"Telah mengungkapkan kepada kami Abu Bakar Abu Syaibah telah mengungkapkan kepada kami wadah Abdul A'la Abdul A'la dari Al Jurairi dari Abu As Salil dari wadah Abdullah Rabah Al Ansari dari Ubay Ka'ab katanya; Nabi Shallallahu 'alaihi wasallam bersabda: "Wahai Abu Mundzir! Tahukah kamu bait Al-Qur'an mana yang kamu miliki yang paling utama?" Abu Mundzir berkata; Saya menjawab, "Allah dan Kurir-Nya yang lebih tahu." Dia bertanya sekali lagi: "Wahai Abu Mundzir, tahukah kamu yang mana dari refrensi Al-Qur'an yang kamu miliki yang utama?" Abu Mundzir berkata; Saya menjawab, "ALLAHU LAA ILAAHA ILLAA HUWAL HAYYUL QAYYUUM." Abu Mundzir berkata; Kemudian, saat itu dia menepuk dadaku dan berkata: "Demi Allah, semoga dadamu penuh dengan informasi, wahai Abu Mundzir."

"Telah mengungkapkan kepada kami Khalid bin Makhlad Telah mengungkapkan kepada kami Sulaiman Telah mengungkapkan kepada kami Abdullah bin Dinar dari Ibnu Umar dari Nabi Shallallahu 'alaihi wasallam, dia berkata: "Pada kenyataannya di antara pepohonan ada satu pohon yang tidak jatuh daunnya. Juga, itu adalah ilustrasi bagi seorang Muslim individu". Nabi Shallallahu 'alaihi wasallam bertanya: "Beritahu saya, pohon apa itu?" Maka para sahabat merasa bahwa yang tersirat adalah sebatang pohon di lembah. Abdullah berkata: Saya pikir dalam hati saya bahwa pohon

\footnotetext{
${ }^{50}$ Maizuddin, Memahami Karakteristik Hadis Nabi (Sebuah Kerangka Dasar Sigh Al-Hadits) (Aceh: Ushuluddin Publishing, 2013).

51 Zul Ikromi, "Fiqh Al-Hadits: Perspektif Metodologis Dalam Memahami Hadits Nabi," Al-Bukhori: Jurnal Ilmu Hadis 3, no. 1 (2020): 105-129.
} 
itu adalah pohon kurma, namun saya malu untuk mengungkapnya. Kemudian, orang-orang itu berkata: "Wahai Rasul Allah, pohon apakah itu?" Beliau Shallallahu 'alaihi wasallam menjawab: "Pohon kurma"

Para ulama sepakat bahwasanya kata shahih ini merupakan istilah untuk hadits yang baik (sehat), tidak sakit, selamat, sempurna dan benar. Sedangkan secara istilah yang dikemukakan oleh Shubhi al-Shalih kata shahih di dalam hadits maknanya adalah sanadnya alurnya bersambung, diriwayatkan oleh periwayat yang berakhlak baik, juga memiliki sifat nalar dan dhabith hingga berproses dan sejalan dengan sabda Nabi atau bisa juga di sanad terakhir, permulaan dari kalangan sahabat tanpa mengandung syadz atau keganjilan juga bukan illat (ketidaksempurnaan). ${ }^{52}$

Tabel 1. Keterangan Hadits

\begin{tabular}{|c|c|c|c|}
\hline $\begin{array}{c}\text { NO } \\
\text { HADITS }\end{array}$ & $\begin{array}{l}\text { STATUS } \\
\text { HADITS }\end{array}$ & PERIWAYAT & SANAD (BIOGRAFI) \\
\hline 1343 & $\begin{array}{l}\text { Shahih } \\
\text { Menurut } \\
\text { Ijma' } \\
\text { para } \\
\text { Ulama }\end{array}$ & $\begin{array}{l}\text { Al-Imam } \\
\text { Abul Husain } \\
\text { Muslim Bin } \\
\text { Ak-Hajjaj Al- } \\
\text { Qusyairi An- } \\
\text { Naisaburi }\end{array}$ & $\begin{array}{l}\text { 1. Ubay bin Ka'ab bin Qais } \\
\text { dari kalangan sahabat, } \\
\text { kuniyah Abu Al-Mundzir, } \\
\text { Negeri yang Tinggal di } \\
\text { Madinah, wafat di 32H } \\
\text { 2. Abdullah bin Rabbah, dari } \\
\text { kalangan Tabi'in } \\
\text { Pertengahan, kuniyah } \\
\text { Abu Khalid, Negeri Hidup } \\
\text { di Basrah, } \\
\text { Dluraib bin Nuqair, dari } \\
\text { kalnagan Tabi'in (tidak } \\
\text { jumpa sahabat), kuniyah } \\
\text { Abu As Sulail, negeri } \\
\text { hidup Bashrah. Ilyas, dari } \\
\text { Sa'id bin biasa, } \\
\text { kalangan Tabi'in Mas'ud, } \\
\text { kuniyah Abu Mashrah, } \\
\text { Negeri hidup di Bashrah }\end{array}$ \\
\hline
\end{tabular}

${ }^{52}$ Tajul Arifin, Ulumul Hadits (Bandung: Gunung Jati Press, 2014). 


\begin{tabular}{|c|c|c|c|}
\hline & & & $\begin{array}{l}\text { 5. Abdul A'laa, Abdul A'laa, } \\
\text { Pusat Tabi'ut Tabi'in, } \\
\text { kuniyah Abu Muhammad, } \\
\text { Tempat Tinggal yang } \\
\text { Terkenal Basrah, wafat } \\
\text { pada 189 H } \\
\text { 6. Abdullah bin Muhammad } \\
\text { Abdullah bin Muhammad } \\
\text { Abi Syaibah Ibrahim } \\
\text { Tabung 'Utsman, dari } \\
\text { Lingkaran Tabi'ul Atba' } \\
\text { lama, Kuniyah Abu Bakar, } \\
\text { Negeri Hidup Kufah, } \\
\text { menendang ember pada } \\
\text { 235 H. }\end{array}$ \\
\hline 60 & $\begin{array}{l}\text { Shahih } \\
\text { Menurut } \\
\text { Ijma' } \\
\text { para } \\
\text { Ulama }\end{array}$ & $\begin{array}{l}\text { Abu } \\
\text { Abdullah } \\
\text { Muhammad } \\
\text { Bin Ismail Bin } \\
\text { Ibrahim Bin } \\
\text { Al-Mughirah } \\
\text { Bin Bardizbah } \\
\text { Al-Bukkhari }\end{array}$ & 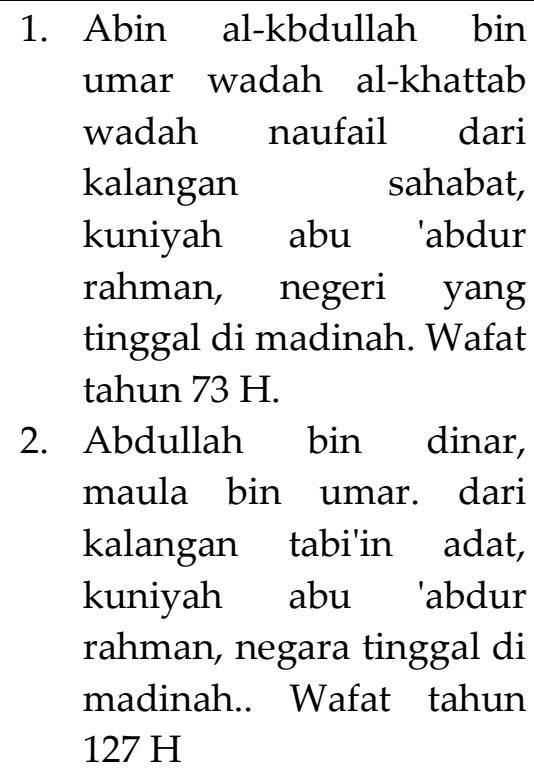 \\
\hline
\end{tabular}

3. Sulaiman bin Bilal, dari kalangan Tabi'ut Tabi;in kalangan pertengahan, kuniah Abu Muhammad, Negeri Hidup di Madinah , Wafat tahun $172 \mathrm{H}$.

4. Khalid bin Makhlad, dari 


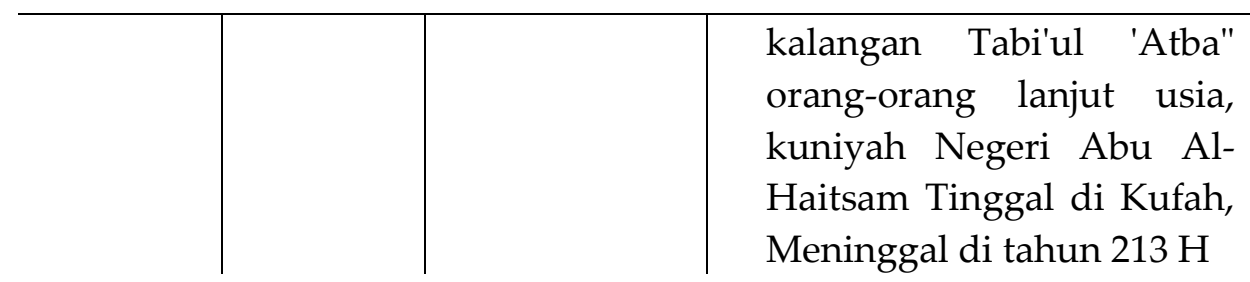

Dalam kedua hadits di atas, dengan jelas menunjukkan bahwasanya dalam proses evaluasi pembealajaran yang diterapkan oleh Rasulullah SAW, sebagai seorang pendidik utama bagi umatnya dengan secara baik dan profesional, dengan cara menguji sahabatnya yaitu Abu Mundzir dan Muadz bin Jabal tentang suatu ilmu atau cara menetapkan sesuatu keputusan. Pengujian (evaluasi) yang beliau terapkan tersebut ia lakukan untuk mengetahui sudah seberapa jauh kapasitas kecerdasan, pemahaman dan ilmu pengetahuan yang sudah dikuasai oleh mereka. Namun dengan jawaban-jawaban yang diberikan oleh sahabat-sahabat Rasululah selalu memuji dan menyanjung mereka. ${ }^{53}$

Dari kedua hadits Rasulullah di atas jelas-jelas menunjukkan adanya pelakasanaan evaluasi pembelajaran yang diterapkan oleh Rasulullah SAW. Sebagai pendidik utama secara baik dan profesional, dimana Rasul menguji sebagian sahabatnya yakni Abu Mundzir dan Muadz bin Jabal tentang suatu ilmu atau cara menetapkan suatu keputusan. Pengujian (evaluasi) yang Rasul berikan biasanya dilakukan agar para sahabat dapat mendapatkan pemahaman yang sesuai dengan harapan Rasulullah. Maka evaluasi sangat penting untuk mengacu pada tujuan karena tujuan bertindak sebagai acuan sehingga dengan jelas menggambarkan apa yang hendak dicapai. ${ }^{54}$

Sebagaimana telah diketahui dan dipahami dari asbab annuzul bahwa dalam QS. al-Ankabut ayat 2-3 disana berbicara mengenai evaluasi yang direalisasikan oleh Allah SWT kepada para penduduk yang tinggal di mekah dan telah memeluk agama islam dan hendak pergi berhijrah dari mekah ke madinah untuk bersama Rasulullah. Dan dalam perjalanan tersebut mereka nyaris ingin terbunuh oleh kaum kafir. Yang mana dalam hal ini Allah SWT tetap menyuruh

\footnotetext{
${ }^{53}$ Ainul Yakin, Hadits-Hadits Pendidikan (Pamekasan: Duta Media, 2017).

${ }^{54}$ Ano Suharna, "Evaluasi Pendidikan Perspektif Islam," Qathruna: Jurnal Keilmuan Dan Pendidikan 3, no. 2 (2016): 49-68.
} 
mereka untuk berhijrah. Dan dalam perjalanan itu pun ada beberapa sahabat yang syahid. Namun sebagian lagi masih tetap hijrah ke madinah untuk bersama Rasul. Dari kisah ini Allah tidak hanya memberikan evalusi kepada Nabi Muhammad dan umatnya akan tetapi kepada nabi dan rasul yang lainnya..$^{55}$

Sementara itu, dalam lembaga pendidikan Islam, istilah evaluasi pendidikan sering kali diartikan sebagai penentuan penilaian dan pengukuran terhadap perkembangan dalam proses sekaligus sebagai sistem untuk mengetahui output dari proses pembelajaran yang telah diperoleh peserta didik selama mengikuti pendidikan dan pembelajaran. Namun penilaian harus dibedakan dengan pengukuran. Sebab penilaian hanya menunjuk kepada suatu kuantitas. Dan disisi lain yang menjadi objek umumnya adalah peserta didik. Namun, dari sudut pandang yang unik, yang tersirat adalah sudut pandang pasti yang ada pada mahasiswa. Sadarilah bahwa siswa dalam pengertian ini benar-benar siswa objek, namun juga bisa menjadi subjek penilaian. Karena pengaturan penilaian pendidikan Islam harus dimungkinkan dua, menjadi penilaian diri yang spesifik dan penilaian orang lain. Untuk situasi ini, objek tujuan khusus dari penilaian pelatihan Islam adalah kemajuan anak/siswa dari perspektif yang berbeda, baik intelektual, penuh perasaan, psikomotorik. ${ }^{56}$

Dengan demikian evaluasi pendidikan yang ada pada zaman sekarang merupakan cara yang dulu selalu dipergunakan oleh Rasulullah dan dilaksanakan pada kehidupan sehari-hari terkadang Rasulullah menguji sahabat untuk melihat pemahaman mereka tentang ajaran agama untuk menyelesaikan berbagai permasalahan dan apa yang Rasulullah ajarkan kepada para sahabatnya bisa mencapai tujuan yang Rasulullah harapkan. Apabila sahabat yang diuji Rasulullah belum sampai kepada hasil yang diharapkan, maka Rasulullah SAW menekankan dan memberikan pemahaman soal dengan diskusi, memberi nasihat atau arahan dan lain-laib. Namun

55 Nurul Hasanah, Lailatul Badriyah, and Wena Diamard Selia, "Evaluasi Pembelajaran Ditinjau Dari Al-Qur'an Surah Al-Ankabut Ayat 2-3," Jurnal Pendidikan Tematik 1, no. 2 (2020): 11-20.

${ }^{56}$ As'ad, "Evaluasi Pendidikan Dalam Perspektif Islam," Jurnal Tazkiyah 8, no. 1 (2019): $33-43$. 
jika hasilnya sesuai dengan yang diharapkan Rasulullah maka beliau akan langsung menyanjung dan memuji. ${ }^{57}$

\section{Kesimpulan}

Evaluasi ialah sebuah kegiatan yang sudah direncanakan yang dibantu oleh alat atau instrumen yang hasilnya menjadi tolak ukur yang diambil kesimpulannya. Dalam lembaga pendidikan islam, istilah evaluasi pendidikan sering kali diartikan sebagai penentuan penilaian dan pengukuran terhadap perkembanagn proses pembelajaran dan sekaligus melihat hasil yang diperoleh peserta didik untuk dijadikan bahan pertimbangan dalam program pembelajaran selanjutnya. Dan hasilnya juga menjadi bahan agar dapat membuat program yang lebih baik sesuai dengan target pencapaian.

Selain al-Qur'an yang menjadi landasan utama dalam hidup manusia terutama dalam bidang pendidikan hadits juga menjadi landasan kuat umat muslim menjadi sumber utama hukum Islam, sedangkan hadits menduduki posisi kedua sebagai dasar hukum umat Islam dalam hal apapun, maka dari itu hadits yang menjadi sumber ini yang tentunya menjadi pedomani haruslah sangat jelas statusnya. Pemahaman tentang berbagai karakteristik hadits jika dilihat susunan matan pada dasarnya adalah sebuah kerangka awal dalam memahami makna hadits Nabi (figh al-hadits). Fiqh al-hadits juga diartikan sebagai sebuah ilmu yang membahas dan memahami tentang isi dari makna yang diperoleh dari lafaz-lafaz hadits dan makna yang dikehendaki pada kepenulisan tersebut. Dari hadits Muslim No. 1343 dan hadits Bukhari No. 60 jelas-jelas menunjukkan adanya pelaksanaan evaluasi pembelajaran yang diterapkan oleh Rasulullah SAW. Sebagai pendidik utama secara baik dan profesional, dimana Rasul menguji sebagian sahabatnya yakni Abu Mundzir dan Muadz bin Jabal tentang suatu ilmu atau cara menetapkan suatu keputusan.

57 Musriaparto, "Kontribusi Hadits Dalam Kitab Al-Bukhari Bagi Sistem Evaluasi Pendidikan," Jihafas: Jurnal Islam Hamzah Fansuri 3, no. 2 (2020): 132-146. 


\section{Daftar Pustaka}

Acree, Jeremy. "Applying the Collaborative Approaches to Evaluation (CAE) Principles in an Educational Evaluation: Reflections from the Field." Canadian Journal of Program Evaluation 34, no. 2 (2019): 272-81. https://doi.org/10.3138/cjpe.53185.

Adib, Helen Sabera, Djemari Mardapi, Zamroni Zamroni, and Adam Jait. "Evaluation of Islam Education Teachers Training Implementation." Jurnal Penelitian Dan Evaluasi Pendidikan 23, no. 2 (December 31, 2019): 106-16. https://doi.org/10.21831/pep.v23i2.20986.

Alabdulhadi, Maali Mohammed Jassim. "Religious Tolerance in Secondary Islamic Education Textbooks in Kuwait." British Journal of Religious Education 41, no. 4 (October 2, 2019): 422-34. https://doi.org/10.1080/01416200.2019.1585329.

Ali, Muhammad, and Didik Himmawan. "Peran Hadits Sebagai Sumber Ajaran Agama, Dalil-Dalil Kehujjahan Hadits Dan Fungsi Hadits Terhadap Al-Qur'an." Risalah: Jurnal Pendidikan Dan Studi Islam 5, no. 1 (2019): $125-32$. https://doi.org/10.5281/zenodo.3551298.

Amna, Arim Zufaida. "Hadis Sebagai Sumber Hukum Islam (Studi Kasus Pandangan Masyarakat Desa Besito-Kudus Terhadap Hadis Larangan Tertawa)." Syariah: Journal of Islamic Law 2, no. 2 (2020): 64-87.

Ar Saravanakumar, Shanmugarevathi, and G.Revathi. Educational Evaluation. Madurai: Shanlax Publications, 2019.

Arifin, Tajul. Ulumul Hadits. Bandung: Gunung Jati Press, 2014.

Arikunto, Suharsimi. Dasar-Dasar Evaluasi Pendidikan. Jakarta: Bumi Aksara, 1993.

As'ad. "Evaluasi Pendidikan Dalam Perspektif Islam." Jurnal Tazkiyah 8, no. 1 (2019): 33-43.

Asnawi, Nur, and Nina Dwi Setyaningsih. "Perceived Service Quality in Indonesian Islamic Higher Education Context: A Test of Islamic Higher Education Service Quality (i-HESQUAL) Model." Journal of International Education in Business 13, no. 1 (April 7, 2020): 107-30. https://doi.org/10.1108/JIEB-11-2019-0054.

Atabik, Ahmad. "Story Repetition in Qur'an as an Islamic Education Learning Strategy." Edukasia: Jurnal Penelitian Pendidikan Islam 15, no. 2 (August 30, 2020): 354. 
https://doi.org/10.21043/edukasia.v15i2.8240.

Davids, Nuraan, and Yusef Waghid. "Ibn Al-Arabi's Idea of Al-Insan Al-Kamil (the Perfect Human) and Democratic Education." Democratic Education and Muslim Philosophy, 2019, 71-79. https://doi.org/10.1007/978-3-030-30056-2_7.

Deswita, Deswita. "Pendidikan Berbasis Kecerdasan Ruhaniah (Membentuk Insan Paripurna/Insan Al-Kamil)." Ta'dib: Jurnal Pendidikan Islam 13, no. 2 (September 27, 2016): 186-97. https://doi.org/10.31958/jt.v13i2.190.

Erawan, Muhammad Aufar Saputra Pratama, Zaid Zaid, Katon Pratondo, and Ahdiana Yuni Lestari. "Predicting Covid-19 Vaccination Intention: The Role of Health Belief Model of Muslim Societies in Yogyakarta." Al-Sihah: The Public Health Science Journal 13, no. 1 (2021): 36-50. https://doi.org/10.24252/alsihah.v13i1.20647.

Faizi, Waqar Un Nisa, and Naeem Butt. "The Origins of Islamic Educational Reformations." Al-Idah 38, no. 2 (November 26, 2020). https://doi.org/10.37556/al-idah.038.02.544.

Gitlin, Andrew, and John Smyth. "Dominant' View of Teacher Evaluation and Appraisal: An International Perspective." Journal of Education for Teaching 14, no. 3 (January 1988): 237-57. https://doi.org/10.1080/0260747880140304.

Guhin, Jeffrey. "The Boundaries of Pragmatism in Muslim Education: Comparing the Islamic Pedagogies of Sayyid Qutb and Fethullah Gülen." Critical Research on Religion 8, no. 3 (December 1, 2020): 257-72. https://doi.org/10.1177/2050303220952866.

Hanafi, Halid, La Adu, and Zainuddin. Ilmu Pendidikan Islam. Yogyakarta: Deepublish, 2018.

Hardaker, Glenn, and Aishah Ahmad Sabki. "A Spiritual Understanding of Islamic Education." In Pedagogy in Islamic Education, 55-62. Emerald Publishing Limited, 2018. https://doi.org/10.1108/978-1-78754-531-120181005.

- - . "The Rise of the Islamic Institution." Pedagogy in Islamic Education, November 19, 2018, 3-16. https://doi.org/10.1108/978-178754-531-120181001.

Hasanah, Nurul, Lailatul Badriyah, and Wena Diamard Selia. “Evaluasi Pembelajaran Ditinjau Dari Al-Qur'an Surah AlAnkabut Ayat 2-3." Jurnal Pendidikan Tematik 1, no. 2 (2020): 11- 
20.

Hussin, Nur Hanani, and Ab Halim Tamuri. "Embedding Values in Teaching Islamic Education among Excellent Teachers." Journal for Multicultural Education 13, no. 1 (March 22, 2019): 2-18. https://doi.org/10.1108/JME-07-2017-0040.

Ikromi, Zul. "Fiqh Al-Hadits: Perspektif Metodologis Dalam Memahami Hadits Nabi." Al-Bukhori: Jurnal Ilmu Hadis 3, no. 1 (2020): 105-29. https://doi.org/10.32505/al-bukhari.v3i1.1534.

Jaya, Septi Aji Fitra. "Al-Qur'an Dan Hadis Sebagai Sumber Hukum Islam." Jurnal Indo-Islamika 9, no. 2 (2019): 204-16. https://doi.org/10.15408/idi.v9i2.17542.

Kaharuddin, Kaharuddin, and Abdus Sahid. "Hadis Sebagai Sumber Hukum Islam: (Tinjauan Paham Inkar As-Sunnah, Syi'ah, Dan Orientalis)." Tajdid: Jurnal Pemikiran Keislaman Dan Kemanusiaan 2, no. 2 (October 31, 2018): 457-67. https://doi.org/10.52266/tadjid.v2i2.174.

Kellaghan, Thomas, and Daniel L. Stufflebeam. International Handbook of Educational Evaluation. International Handbook of Educational Evaluation. $\quad$ Springer Netherlands, 2003. https://doi.org/10.1007/978-94-010-0309-4.

Khadijah, Mohd Khambali Hambali, Suraya Sintang, Azarudin Awang, Khairul Nizam Mat Karim, Nur Farhana Abdul Rahman, Wan Adli Wan Ramli, Nurhanisah Senin, et al. "Al-Wasatiyyah in the Practice of Religious Tolerance among the Families of New Muslims in Sustaining a Well-Being Society." Humanomics 33, no. 2 (2017): 211-20. https://doi.org/10.1108/H-02-2017-0025.

Mahfud, Choirul. "Evaluation of Islamic Education Curriculum Policy in Indonesia." Premiere Educandum: Jurnal Pendidikan Dasar Dan Pembelajaran 9, no. 1 (June 21, 2019): 34-43. https://doi.org/10.25273/pe.v9i1.4016.

Maizuddin. Memahami Karakteristik Hadis Nabi (Sebuah Kerangka Dasar Siqh Al-Hadits). Aceh: Ushuluddin Publishing, 2013.

Malawi, Ibadullah, and Endang Sri Maruti. Evaluasi Pendidikan. Magetan: CV. Ae Media Grafika, 2016.

Marshallsay, Zaniah. "Twists and Turns of Islamic Education across the Islamic World." International Journal of Pedagogies and Learning 7, no. 3 (2012): 180-90. https://doi.org/10.5172/ijpl.2012.7.3.180.

Marzuki, Ismail, and Lukmanul Hakim. "Evaluasi Pendidikan Islam." 
Jurnal Tadarus Tarbawy 1, no. 1 (2019): 77-84. https://doi.org/10.31000/jkip.v1i1.1498.

Maulida, Ali. "Metode Dan Evaluasi Pendidikan Akhlak Dalam Hadits Nabawi." Edukasi Islami Jurnal Pendidikan Islam 04, no. 07 (October 25, 2015): 855-69. https://doi.org/10.30868/EI.V4I07.66.

Miswanto. "Evaluasi Pendidikan Agama Islam Berbasis Karakter." Jurnall Ilmiah Madaniyah 4, no. 2 (2014): 151-64.

Munawwir, Ahmad Warson. Kamus Al-Munawwir Arab Indonesia Terlengkap. Surabaya: Pustaka Progresif, 2002.

Musriaparto. "Kontribusi Hadits Dalam Kitab Al-Bukhari Bagi Sistem Evaluasi Pendidikan." Jihafas: Jurnal Islam Hamzah Fansuri 3, no. 2 (2020): 132-46.

Rafik, Abdur, and Anjar Priyono. "A New Insight into Alumni Satisfaction Model for Islamic Higher Education Institutions (IHEI)." Management Research Review 41, no. 12 (October 24, 2018): 1411-37. https://doi.org/10.1108/MRR-01-2017-0005.

Rassouli, Aman, and Necdet Osam. "English Language Education Throughout Islamic Republic Reign in Iran: Government Policies and People's Attitudes." SAGE Open 9, no. 2 (April 1, 2019): 1-11. https://doi.org/10.1177/2158244019858435.

Rodiyah, Siti Kholidatur. "Ideal Evaluation in Islamic Education Learning." Edutec: Journal Of Education And Technology 2, no. 2 (2019): 1-5. https://doi.org/10.29062/edu.v2i2.23.

Sari, Lia Mega. “Evaluasi Dalam Pendidikan Islam." Al-Tazkiyah Jurnal Pendidikan Islam 9, no. 2 (2018): 211-31. https://doi.org/10.24042/atjpi.v9i2.3624.

Scriven, Michael. "Evaluation Theory and Metatheory." International Handbook of Educational Evaluation 9 (2003): 15-30. https://doi.org/10.1007/978-94-010-0309-4_3.

Suharna, Ano. "Evaluasi Pendidikan Perspektif Islam." Qathruna: Jurnal Keilmuan Dan Pendidikan 3, no. 2 (2016): 49-68.

Supriyadi. Evaluasi Pendidikan. Pekalongan: Nasya Expanding, 2021.

Surawan, and Muhammad Athaillah. Ilmu Pendidikan Islam. Yogyakarta: K-Media, 2021.

Szokol, Istvan, and Kinga Horvath. "The Dimensions of Educational Evaluation." Kepzes Es Gyakorlat 14, no. 3-4 (2016). https://doi.org/10.17165/tp.2016.3-4.16.

T. Manichander. Evaluation in Education. Hillsborough St, Raleigh: 
Lulu Publication, 2016.

Tasbih, Tasbih. "Kedudukan Dan Fungsi Hadis Sebagai Sumber Hukum Islam." Jurnal Ushuluddin: Media Dialog Pemikiran Islam 14, no. 3 (March 28, 2017): 331-41.

Tjabolo, Siti Asiah, and Lian Gafar Otaya. "The Evaluation of Islamic Education Teachers' Performance." Jurnal Pendidikan Islam 5, no. 1 (2019): 25-38. https://doi.org/10.15575/jpi.v5i1.3627.

Ummah, Siti Syamsiyatul. “Digitalisasi Hadis (Studi Hadis Di Era Digital)." Diroyah: Jurnal Studi Ilmu Hadis 4, no. 1 (September 30, 2019): 1-10. https://doi.org/10.15575/DIROYAH.V4I1.6010.

Wahab, Fatkhul. "Kedudukan Hadis Dalam Penetapan Hukum." Maqashid: Jurnal Hukum Islam 2, no. 1 (May 28, 2019): 1-14. https://doi.org/10.35897/maqashid.v2i1.179.

Yakin, Ainul. Hadits-Hadits Pendidikan. Pamekasan: Duta Media, 2017.

Zainab, Nurul. "Model Evaluasi Pendidikan Berbasis Proses Menurut Hadis." Jurnal Al-Banjari 17, no. 1 (2018): 153-72. https://doi.org/10.18592/al-banjari.v17i1.1465.

Zhanjun, Wang, Qiao Weifeng, and Li Jiangbo. "Data-Intensive Evaluation: The Concept, Methods, and Prospects of Higher Education Monitoring Evaluation." Chinese Education and Society 49, no. 1-2 (March 3, 2016): 86-98. https://doi.org/10.1080/10611932.2016.1192400.

Zubaidillah, Muh Haris. "Prinsip Dan Alat Evaluasi Dalam Pendidikan." OSF Preprints, 2018, 1-13. https://doi.org/10.31219/osf.io/4tgfm.

Zuhairini. Filsafat Pendidikan Islam. Jakarta: Bumi Aksara, 1995. 